\title{
Climate change impacts on water sustainability in the Nam Ngum River Basin of Laos
}

\author{
D. Jayasekera \& J. J. Kaluarachchi \\ College of Engineering, Utah State University, USA
}

\begin{abstract}
The Nam Ngum River Basin (NNRB) in Laos has received wide attention from foreign investors due to its high hydropower development potential and low per capita electricity consumption. The NNRB is rapidly developing due to its hydropower generation potentials while water demands will increase for agricultural and domestic purposes due to population increase and land-use changes. Water availability will be affected with the increasing water demand and climate change may worsen the water availability conditions. On a regional scale, climate change impact assessment is crucial for water resource planning, management and decision making. In the first part of this study, reliable estimation of climatic variables is performed under climate change. The second part assesses the changes in water resources regimes and sustainability conditions of agricultural and domestic water user sectors under climate change for the 'do nothing' option that are critical for strategic planning and to minimize the negative impacts. Third part assesses the long-term climate change trends, water allocation challenges and appropriate adaptation measures to minimize watershed impacts to achieve sustainability and long-term management goals. The major findings of this study show wetter and warmer climates, especially in the latter part of the century, indicating less water availability and sustainability in meeting the water demands for agriculture and domestic use is affected under the 'do nothing' option.

Keywords: Laos, Nam Ngum River Basin, climate change.
\end{abstract}

\section{Introduction}

The Nam Ngum River Basin (NNRB) is a part of the Mekong River Basin undergoing rapid changes due to economic growth, land use changes, and population growth. Previous work focused on understanding the climate change 
impacts and predicted the hydrologic regime changes under climate change [1]. Jayasekara [1] demonstrated the applicability of a water resources planning system to assess the hydrologic response and watershed impacts due to projected climate change. Jayasekera [1] developed a Water Evaluation and Planning System (WEAP21) modeling framework at the watershed-scale, incorporating the climate change driven hydrologic cycle and water infrastructure operations, such as dams for hydropower and water storage and diversions for irrigation. The results from both studies showed climate change affects rainfall and potential evapotranspiration (PET). A significant increase in rainfall was observed in the dry season but a high percent increase of PET, mostly in the northern and southern parts of the NNRB, was also noticed using CGCM3.1 T63 data for the 21st century. Given the hydrologic impacts due to climate change and human induced water infrastructure and land use changes, the NNRB may require adaptation measures to overcome potential negative impacts due to climate change. As a first step in this direction, this study investigates the trends of hydrologic and watershed responses under climate change to confirm adaptation measures are needed. If there are negative impacts, then adaptation strategies are investigated.

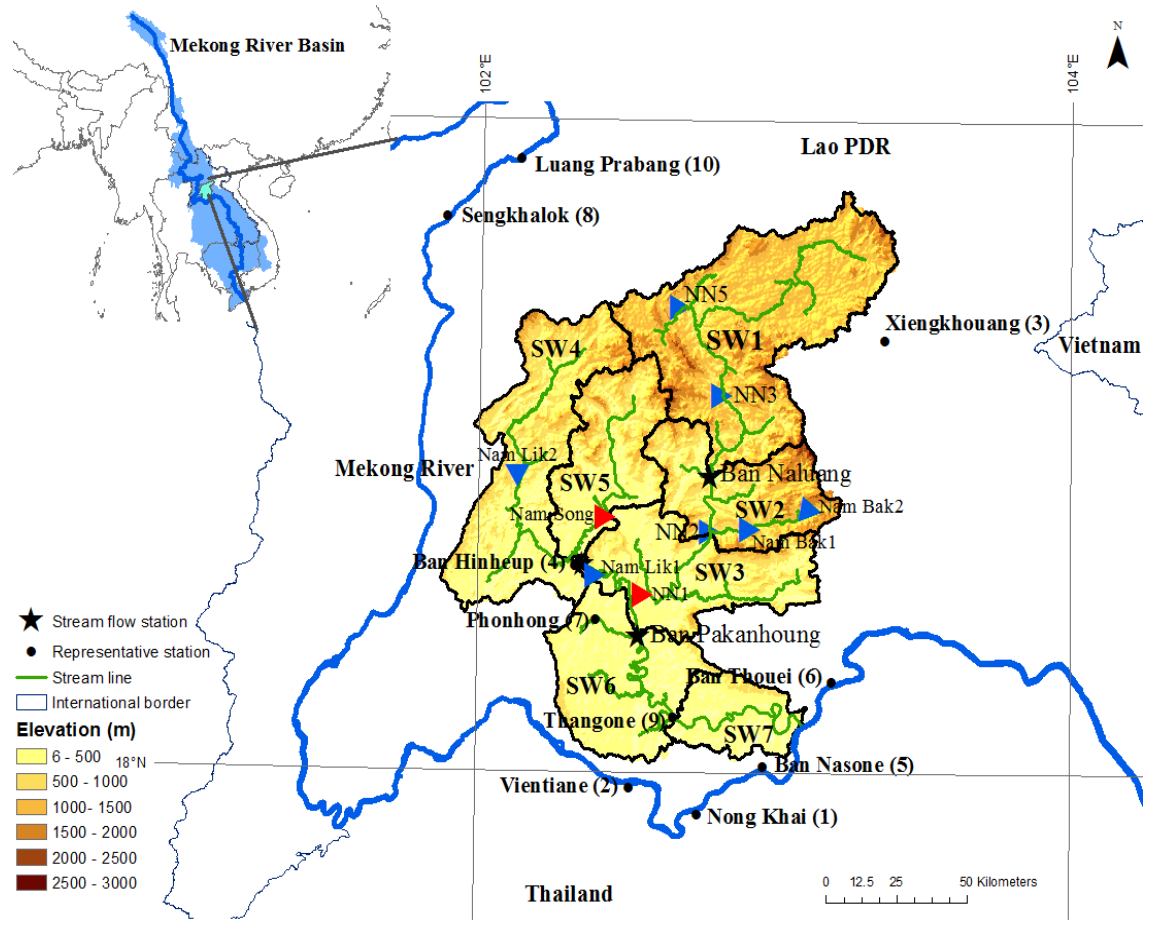

Figure 1: Physical layout of the NNRB of Laos, showing watersheds and other key features. Red shows existing and blue shows planned reservoirs. Construction/planning stage (blue) reservoirs/dams. 


\section{Description}

The climate of NNRB is subtropical to tropical with a distinct wet season from May to October and mostly dry during the rest of the year. Most of the precipitation in the NNRB is due to the arrival of warm moist air during the southwest monsoon period. The hottest months are March to April during which the mean daily maximum temperature varies between from $28^{\circ}$ to $34^{\circ} \mathrm{C}$. The mean minimum daily temperature varies between $14^{\circ}$ and $24^{\circ} \mathrm{C}$ between December and January at high elevations [2]. The mean annual precipitation of NNRB is 2000 $\mathrm{mm}$, varying between 1400 to more than $3500 \mathrm{~mm}$ [3]. The mean annual PenmanMonteith potential evapotranspiration varies between $1060 \mathrm{~mm}$ and $1360 \mathrm{~mm}$ [2]. The mean annual flow to the Mekong River is about 22 billion $\mathrm{m}^{3}$ (BCM) which is about $14.4 \%$ of the annual flow of the Mekong River. The annual water use of $\mathrm{NNRB}$ is about $0.9 \mathrm{BCM}$ of which $99 \%$ is used by agriculture, $0.52 \%$ is by domestic water use, and $0.08 \%$ is for industrial purposes.

\section{Climate change analysis}

This study extended the work of Kim et al. [4] to generate future precipitation under climate change using a discrete-time/space Markov chain based on historical conditional probabilities. A bias-correction method is proposed by fitting suitable statistical distributions to transform precipitation from the general circulation model (GCM) scale to watershed scale. This work generated weekly precipitation for a 100-year period using historical precipitation data from 1961 to 2000 for ten selected weather stations. The simulated precipitation series is perturbed using the delta change estimated at each station to project future precipitation for the Special Report on Emission Scenarios (SRES) A2. The A2 emission scenario is the most common scenario for mid and high ranges of emissions used in recent climate change impact studies [5,6], and for South East Asia by Lacombe et al. [7]. In this study, CGCM3.1 T63 (http://www.ec.gc.ca/ccmac-cccma/default.asp?lang=En\& $\mathrm{n}=1299529 \mathrm{~F}-1$ ) and ECHAM5 (http://www.mpimet.mpg.de/en/science/models/ echam/echam5.html) were selected based on the ability to represent the temporal and spatial patterns of precipitation over the Mekong Basin. In addition, a RCM known as PRECIS (Providing Regional Climates for Impacts Studies) developed by the Hadley Center for Climate Change in UK is available for comparison with projections made by other GCMs (http://www.metoffice.gov.uk/precis, accessed March, 2012). RCM simulations for the NNRB were conducted by the South East Asia Regional Center (START) in Thailand. (http://www.start.or.th/, accessed March, 2012).

Table 1 shows the comparison of areal mean monthly precipitation amounts estimated using the historical observed, GCM bias corrected baseline scenario, and RCM control for the period from 1961 to 2000. The projected precipitation was for two time periods, $2011-050$ and 2050-2100. For simplicity, the results shown here are for the latter time period only. The perturbed precipitation series for the 10 stations used in this study were spatially averaged for each GCM. As shown in Table 1, each GCM shows different increases but with less inter-model 
difference for both monthly and annual precipitation. Both models projected an increase in the total annual precipitation. The results show that both CGCM3.1 and ECHAM5 produced an increase of total annual precipitation of $13 \%$, for the time period 2051-2090.

The seasonal variation of precipitation is important information where variation of streamflow can occur due to the changes in precipitation. Wet season precipitation contributes $76 \%$ whereas dry season precipitation contributes $24 \%$ to the mean annual precipitation from 1961 to 2000. Both CGCM and ECHAM projected that the wet season precipitation contributes $75 \%$ whereas the dry season precipitation contributes $25 \%$ to the mean annual precipitation from 2011 to 2050 while the wet season contributes $72 \%$ and the dry season contributes $28 \%$ from 2051 to 2090 . These statistics indicate that during the latter half of the century there will be an increase in mean dry season precipitation compared to the first half of the century. Table 1. Comparison between historical observation and projected mean monthly precipitation (in $\mathrm{mm}$ ) for A2 scenario using PRISM RCM and the two GCMs for the latter part of the century.

Table 1: Comparison between historical observation and projected mean monthly precipitation (in $\mathrm{mm}$ ) for A2 scenario using PRISM RCM and the two GCMs for the latter part of the century.

\begin{tabular}{lcccccc}
\hline Month & (1961-2000) & $\mathbf{( 1 9 6 1 - 2 0 0 0 )}$ & Baseline & $\begin{array}{c}\text { A2 } \\
\text { 2051-2090 }\end{array}$ & $\begin{array}{c}\text { 20C3M } \\
\text { Baseline Scenario }\end{array}$ & $\begin{array}{c}\text { A2 2051-2090 } \\
\text { Jan }\end{array}$ \\
\hline Feb & 53.9 & 4.1 & 53.9 & 82.0 & 53.7 & 82.4 \\
Mar & 53.8 & 6.4 & 53.8 & 65.7 & 53.6 & 66.0 \\
Apr & 75.3 & 18.1 & 75.3 & 88.8 & 76.0 & 89.2 \\
May & 117.7 & 55.1 & 117.5 & 148.9 & 119.7 & 144.7 \\
Jun & 226.2 & 132.1 & 225.8 & 233.9 & 226.5 & 234.3 \\
Jul & 257.5 & 322.6 & 257.2 & 252.2 & 257.3 & 251.4 \\
Aug & 259.2 & 314.1 & 258.9 & 299.5 & 258.9 & 299.7 \\
Sep & 283.9 & 277.6 & 283.7 & 284.7 & 283.8 & 284.8 \\
Oct & 194.0 & 146.1 & 192.9 & 226.8 & 195.1 & 225.4 \\
Nov & 98.8 & 36.9 & 98.9 & 123.4 & 98.9 & 123.5 \\
Dec & 57.2 & 7.5 & 57.0 & 93.3 & 55.9 & 95.9 \\
\hline Annual & 1732.4 & 2.2 & 54.4 & 60.5 & 54.1 & 60.7 \\
\hline
\end{tabular}

Table 2 provides a quantitative comparison of statistics of projected areal precipitation for wet and dry seasons of the study area. The maximum and minimum percent change of mean annual precipitation is $14.7 \%$ and $8.7 \%$ for CGCM3.1 and ECHAM5 scenarios, respectively, from 2011 to 2050. Both GCM projections are in agreement to show that maximum and minimum mean annual 
precipitations will increase during the next 80 years and the maximum and minimum mean annual will significantly increase during the second half of the century. Figure 2 shows the projected spatial distributions of precipitation using the two GCMs.

Table 2: Percent changes of projected areal precipitation from historical precipitation.

\begin{tabular}{llcccc}
\hline \multirow{2}{*}{ Season } & \multirow{2}{*}{ Statistics } & \multicolumn{2}{c}{ CGCM3.1 } & \multicolumn{2}{c}{ ECHAM5 } \\
& & 2011-2050 & 2051-2090 & 2011-2050 & 2051-2090 \\
\hline \multirow{2}{*}{ Annual } & Max & 14.7 & 12.0 & 9.6 & 11.9 \\
& Mean & 11.8 & 13.1 & 11.6 & 13.0 \\
& Min & 19.4 & 22.3 & 8.7 & 15.4 \\
\hline \multirow{3}{*}{ Wet } & Max & 9.1 & 13.8 & 8.8 & 14.0 \\
& Mean & 9.7 & 7.6 & 9.4 & 7.5 \\
\hdashline & Min & 1.1 & -2.8 & 0.4 & -3.0 \\
\hline \multirow{2}{*}{ Dry } & Max & 23.3 & 38.0 & 22.2 & 37.9 \\
& Mean & 18.2 & 30.7 & 18.5 & 30.6 \\
& Min & -1.6 & -25.5 & -1.4 & -25.5 \\
\hline
\end{tabular}

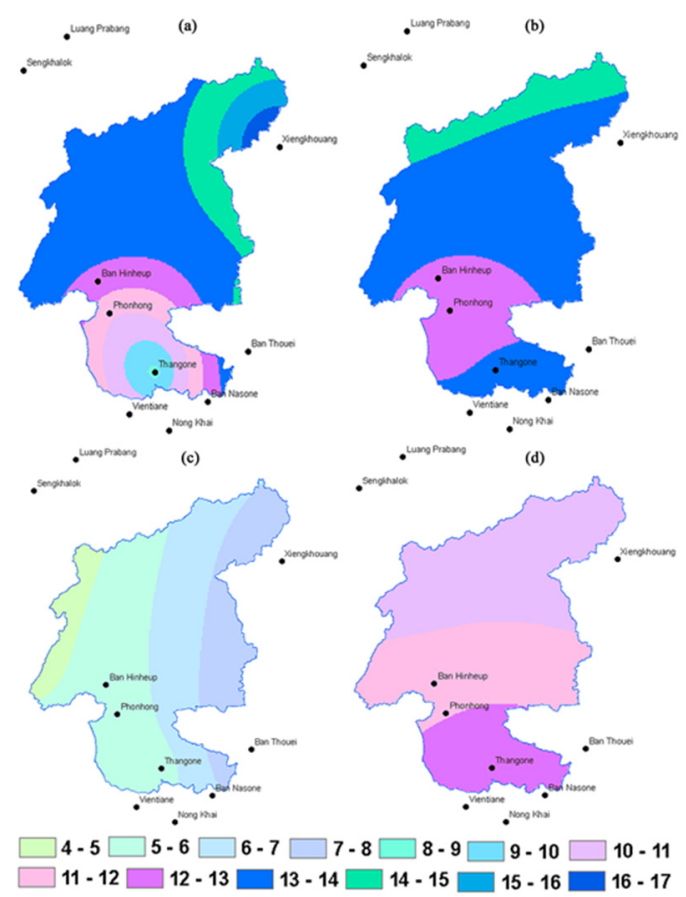

Figure 2: Spatial distributions of percent changes in mean annual precipitation from 2011 to 2090: (a) CGCM (2011-2050), (b) CGCM (20512090), (c) ECHAM (2011-2050), and (d) ECHAM (2051-2090). 


\section{Water resources analysis}

The results from the climate change analysis using the A2 emission scenario and CGCM3.1 T63 were used in the initial water resources analysis. Table 3 shows climate change driven seasonal changes for the 40 year future time periods (such as the wet and dry season) and average changes in rainfall (P), potential evapotranspiration (PET), and aridity compared to the baseline period. Percent changes in the aridity index is preferred because it reflects the percent changes in rainfall and the overall changes of other meteorological variables such as temperature, relative humidity, and wind speed under different climatic conditions. The overall watershed hydro-climatology of the NNRB remains "humid" under the existing and future climatic conditions. In the first half of the century dry conditions were exhibited by WS1, WS6, and WS7 due to the increase of PET. However, these extremes are somewhat minimized in the same time period by increased rainfall as high as $58.6 \%$ from the average values. Therefore, aridity in the first part of the century does not appear to be high, except marginally with WS7. When comparing the wet and dry seasons for the same time period, the observations are similar because the increased PET is counterbalanced by increased rainfall. In general WS7 was most affected, with a high increase of PET and a marginal increase of rainfall, making this watershed more arid than the baseline period.

Table 3: Comparison of percent changes of PET and P compared to the baseline period of 1991-1998. W and D denotes wet and dry periods.

\begin{tabular}{|c|c|c|c|c|c|c|c|c|}
\hline \multirow{3}{*}{ Watershed } & \multicolumn{4}{|c|}{$\%$ change in PET } & \multicolumn{4}{|c|}{$\%$ change in $P$} \\
\hline & \multicolumn{2}{|c|}{ 2011-2050 } & \multicolumn{2}{|c|}{$2050-2100$} & \multicolumn{2}{|c|}{ 2011-2050 } & \multicolumn{2}{|c|}{$2050-2100$} \\
\hline & $\mathbf{W}$ & D & $\mathbf{W}$ & D & $\mathbf{W}$ & D & $\mathbf{W}$ & D \\
\hline WS1 & 18.7 & 18.9 & 52.7 & 53.5 & 28.0 & 45.1 & 19.5 & 54.1 \\
\hline WS2 & 9.2 & 9.9 & 18.5 & 19.8 & 26.7 & 46.3 & 26.9 & 64.4 \\
\hline WS3 & -13.3 & -12.9 & -38.6 & -38.1 & 11.2 & 39.8 & 8.7 & 48.9 \\
\hline WS4 & -0.3 & -0.2 & -0.9 & -0.4 & 36.6 & 58.9 & 40.9 & 84.2 \\
\hline WS5 & 0.4 & 0.5 & 0.8 & 1.3 & 40.3 & 76.9 & 42.0 & 110.8 \\
\hline WS6 & 24.8 & 25.4 & 85.7 & 87.3 & 2.1 & 32.6 & 2.8 & 24.6 \\
\hline WS7 & 27.7 & 28.7 & 90.0 & 92.2 & 9.9 & 7.6 & 12.1 & 5.7 \\
\hline
\end{tabular}

The predicted hydrologic-climate regime in the second half of the century is similar in trend except the changes in PET are much higher. WS1, WS2, WS6, and WS7 consistently show a higher increase of PET compared to the first part of the century. Rainfall, on the other hand, has increased significantly compared to the first part of the century, making the NNRB more humid. As before, WS7 is affected much more in the second part of the century, with a lower percent of increase in dry season rainfall as opposed to high increases in PET, compared to the first part of the century, and also compared to all other watersheds, indicating climate change impacts are significant. The rainfall patterns show that the average rainfall amounts increase compared to the baseline period across the NNRB for 
the future time periods. The wet season average rainfall amounts increase approximately by $15 \%$ and $13 \%$, whereas the dry season rainfall amounts increase by $40 \%$ and $53 \%$ from 2011 to 2050 , and from 2051 to 2090 , respectively. The percent increase in rainfall is significantly higher in the northern and central parts compared to the southern parts of the NNRB. It is also notable that the percent changes in rainfall are relatively higher in the dry season compared to the wet season. The maximum percent increase in rainfall during the wet and dry seasons is observed in WS5 compared to other watersheds.

To estimate the overall watershed impacts of the NNRB, the changes in average annual flow at the outlet to the Mekong River were calculated. Compared to the baseline period, Table 4 shows that the average annual flow at outlet decreases by $60 \%$ and $72 \%$ from 2011 to 2050 , and from 2051 to 2090 , respectively. It is shown that the average annual flow reduction for future time period from 2011 to 2018 and from 2051 to 2058 are similar compared to the flow reductions for 40 years future time periods. Moreover, wet season streamflow at the outlet decreases by $53 \%$ and $62 \%$ from 2011 to 2050 , and from 2051 to 2090 , respectively whereas the dry season percent flow reduction is $74 \%$ and $92 \%$ for the same time periods. In terms of flow reduction, a significant decrease in streamflow at the outlet is observed during the second half of the century. Possible reasons for this flow reduction even with a high percent of increased rainfall in the dry season are, (1) equal priority for hydropower generation and therefore reservoirs are filling up and there is increased water storage in large upstream reservoirs, (2) relatively high PET compared to the increasing rainfall in downstream watersheds, namely WS6 and WS7, (3) high agricultural water demand, especially for paddy, and (4) high domestic water use.

Table 4: Comparison of changes in annual streamflow volume at the outlet of the NNRB. The values in parentheses are percent changes from the baseline scenario. Note two reservoirs are operating during the baseline period (1991-1998) and nine reservoirs are planned the period (2011-2090).

\begin{tabular}{lc|c|c|c|c}
\hline & \multicolumn{5}{c}{ Streamflow (billion cubic meters) } \\
\cline { 2 - 6 } Season & Observed & \multicolumn{4}{|c}{ With proposed reservoirs/dams } \\
\cline { 2 - 6 } & $\begin{array}{c}\text { Baseline } \\
(\mathbf{1 9 9 1 - 1 9 9 8 )}\end{array}$ & $\begin{array}{c}\mathbf{A 2} \\
\mathbf{( 2 0 1 1 - 2 0 1 8 )}\end{array}$ & $\begin{array}{c}\mathbf{A 2} \\
\mathbf{( 2 0 5 1 - 2 0 5 8 )}\end{array}$ & $\begin{array}{c}\mathbf{A 2} \\
\mathbf{( 2 0 1 1 - 2 0 5 0 )}\end{array}$ & $\begin{array}{c}\mathbf{A 2} \\
\mathbf{( 2 0 5 1 - 2 0 9 0 )}\end{array}$ \\
\hline \multirow{2}{*}{ Wet } & 12.8 & $5.8(-55)$ & $4.9(-62)$ & $6.0(-53)$ & $4.8(-62)$ \\
Dry & 6.4 & $2.3(-64)$ & $0.6(-91)$ & $1.7(-74)$ & $0.5(-92)$ \\
Annual & 19.2 & $8.1(-58)$ & $5.4(-72)$ & $7.6(-60)$ & $5.3(-72)$ \\
\hline
\end{tabular}

\section{Summary}

This work studied the climate change impacts on hydrology and water resources on the NNRB of Laos. This work included a bias-correction method to downscale from the GCM scale of climatic variables to multiple sites to construct the baseline 
scenario. Future climatic variables are estimated by adopting the bias-correction method using the future climate change A2 emission scenario. This work used outcomes of CGCM3.1 T63, ECHAM5 and PRECIS RCM to identify the ability of representing the climate for the baseline period (1961 to 2000).

As a result, the climate change scenario showed that the spatial distribution of projected mean annual precipitation showed a significant increase in the northeastern and central parts of the study area. The highest percent changes of mean annual precipitation are about 13\% from both CGCM and ECHAM for 2051 through 2090, whereas they were $12 \%$ and $11 \%$ from CGCM and ECHAM for 2011 through 2050, respectively, while showing small inter-model differences. The highest precipitation increase during the dry season was $31 \%$ from 2051 to 2090. The projected percent increase in potential evapotranspiration for the future A2 emission scenario over the study area, compared to the baseline period, is $8 \%$ and $22 \%$ from 2011 to 2050 and from 2051 to 2090 , respectively.

The integrated water resources management modeling framework developed in WEAP21 successfully simulated natural historical flow regimes and water allocation under the equal priority scenario of the NNRB of Laos. The model considers the hydrologic processes and water infrastructure operations and was used in assessing climate change impacts under status-quo conditions. This modeling framework aids in estimating the watershed impacts in terms of unmet water demands at the watershed scale and sustainability in meeting water demands for different water users and groups. Sustainability is estimated using the reliability, resiliency, and vulnerability of each water user and for each water user group.

For water resources analysis, the projected climate change was simulated using CGCM3.1 T63, and the A2 scenario that provides probably the worst case scenario. The agricultural sector is critically affected showing unsustainable conditions during both future time periods compared to the domestic water use sector, mainly in the upper parts of the NNRB. Under the status-quo conditions, critical conditions occur in terms of streamflow reduction at the main outlet, the amount of hydropower generated, and sustainability in meeting water demands during the period from 2051 to 2090. Annual wet and dry season streamflow is reduced by $72 \%, 62 \%$, and $92 \%$ compared to the baseline period, during the latter part of the century. The amount of hydropower generation is reduced for every allocation scenario and is reduced by about $9 \%$ under the equal priority scenario compared to the first half. The agricultural and domestic water user group sustainability index is reduced by $97 \%$ and $60 \%$, respectively, compared to the baseline conditions during the second half of the century.

\section{References}

[1] Jayasekara, D., 2013. Impacts of climate change on water resources and corresponding adaptation strategies of the Nam Ngum River Basin, Laos, PhD Dissertation, Utah State University.

[2] ADB (Asian Development Bank) (2008). Lao People's Democratic Republic: Preparing the Cumulative Impact Assessment for the Nam Ngum 3 
Hydropower Project, Technical Assistance Consultant's Report, Project Number 40514, Financed by the Japan Special Fund) Prepared by Vattenfall Power Consultant AB in association with Ramboll Natura AB and Earth Systems Lao, February 2008.

[3] WREA (Water Resources and Environment Administration), (2008). Nam Ngum River Basin profile. Prepared under the Nam Ngum river basin development project, supported by the Asian Development Bank (Loan 1933LAO) and Agence Francaise de Development (Grant CLA 1048 01H), June 2008.

[4] Kim, U., J. J. Kaluarachchi, and V. U. Smakhtin (2008). Generation of Monthly Rainfall under Climate Change for the Upper Blue Nile River Basin, Ethiopia. Journal of the American Water Resources Association (JAWRA) Vol. 44(5), pp. 1231-1247. DOI: 10.1111/j.1752-1688.2008.00220.x.

[5] Abbaspour, K. C., M. Faramarzi, S. S. Ghasemi, and H. Yang (2009). Assessing the impact of climate change on water resources in Iran, Water Resources Research, Vol. 45, W10434. DOI: 10.1029/2008WR007615.

[6] Sulis, M. C. Paniconi, C. Rivard, R. Harvey, and D. Chaumont (2011). Assessment of climate change impacts at the catchment scale with a detailed hydrological model of surface-subsurface interactions and comparison with a land surface model, Water Resources Research, 47, W01513. DOI: 10.1029/2010WR009167.

[7] Lacombe, G., V. Smakhtin, and C.T. Hoanh (2010). Rainfall trends in the Central Mekong Basin: 1953-2004, International Journal of Climatology (in review). 